\title{
Alterations in the red blood cell membrane proteome in alzheimer's subjects reflect disease-related changes and provide insight into altered cell morphology
}

\author{
Joy G Mohanty ${ }^{1 *}$, Hem D Shukla ${ }^{1}$, Jefferey D Williamson ${ }^{2}$, Lenore J Launer ${ }^{3}$, Satya Saxena ${ }^{1}$, Joseph M Rifkind ${ }^{1}$
}

\begin{abstract}
Background: Our earlier studies have shown that red blood cell (RBC) morphology in Alzheimer's disease (AD) subjects was altered ( $>15 \%$ of the RBCs were elongated as compared to $5.9 \%$ in normal controls $(p<0.0001)$ ). These results suggested alterations in the RBC membrane architecture in $A D$ subjects, possibly due to RBC- $\beta$-amyloid interactions and/or changes in the expression of membrane proteins. We hypothesized that the observed changes could be due to changes in the level of the protein components of the cytoskeleton and those linked to the RBC membrane. To examine this, we performed a proteomic analysis of RBC membrane proteins of AD subjects, and their age-matched controls using one pool of samples from each group, following their separation by SDS-PAGE, in-gel Tryptic digestion, LC-MS-MS of peptides generated, and a label-free approach of semi-quantitative analysis of their relative MS spectral intensities.

Results: The data suggest, (1) RBC shape/morphology changes in AD subjects are possibly attributed primarily to the changes (elevation or decrease) in the level of a series of membrane/cytoskeleton proteins involved in regulating the stability and elasticity of the RBC membrane, and (2) changes (elevation or decrease) in the level of a second series of proteins in the RBC membrane proteome reflect similar changes reported earlier by various investigators in $A D$ or animal model of $A D$. Of particular interest, elevation of oxidative stress response proteins such as heat shock $90 \mathrm{kDa}$ protein 1 alpha in AD subjects has been confirmed by western blot analysis in the RBC membrane proteome.
\end{abstract}

Conclusions: The results suggest that this study provides a potential link between the alterations in RBC membrane proteome in AD subjects and AD pathology.

\section{Background}

Alzheimer's disease (AD) is a progressive neurodegenerative disorder characterized by abnormal extracellular deposition of $\beta$-amyloid (A $\beta$ ) peptide and neuronal loss. Recently, we have analyzed red blood cell (RBC) morphology in blood from subjects with AD and reported [1] that $>15 \%$ of the RBCs are elongated as compared to $5.9 \%$ in normal controls ( $\mathrm{p}<0.0001$ ). This observation suggests possible alterations in the RBC membrane architecture in AD subjects. These changes are likely to originate from modifications caused by $\mathrm{A} \beta$ interactions

\footnotetext{
* Correspondence: Mohanty」@mail.nih.gov

${ }^{1}$ National Institute on Aging, Baltimore, MD, USA
}

with RBCs [2,3] and/or changes in the expression level of certain $\mathrm{RBC}$ proteins.

It is well established [4] that the cytoplasmic surface of the RBC plasma membrane contains a two-dimensional meshwork of proteins referred to as the spectrin membrane cytoskeleton. Attached to integral membrane proteins, this cytoskeleton provides elasticity, flexibility and stability to the RBC, as the cells continuously flow through the circulatory system. Passage through the narrow blood vessels and micro capillaries involve large changes in shear stress and significant deformation of the RBC. Because of the ease in obtaining RBCs and the lack of internal RBC organelles, the plasma membrane of these cells has been extensively studied. The identity, 
function, and topology of many $\mathrm{RBC}$ membrane proteins have been determined [4-6]. A number of proteins associated with the RBC cytoskeleton have been shown to alter the shape of RBCs. Therefore, we hypothesized that the observed increase in RBCs with a non-biconcave shape from AD subjects [1], could be traced back to changes in the level of the protein components of the cytoskeleton and the proteins linking the cytoskeleton to the membrane.

A recent review published by Goodman et. al. [7], compiled the proteomic data on RBC proteins gathered over the last five years by several laboratories. These studies identified 751 proteins within the human erythrocyte, including about 340 membrane proteins reported by Pasini et. al. in 2006 [8]. Many of the identified proteins were shown to play a role in regulating the shape and stability of the RBC. Therefore, we performed a proteomic analysis of $\mathrm{RBC}$ membrane proteins of $\mathrm{AD}$ subjects, and their age-matched controls, to see if we can explain the observed RBC shape changes in AD subjects [1], and to determine whether $\mathrm{RBC}$ membrane proteomics reflect changes in the level of proteins linked to AD pathology.

\section{Results and Discussion}

\section{LC-MS-MS data from RBC membrane proteins}

As described in the Methods section below, membrane proteins were prepared from two RBC pools (AD and normal controls) consisting of 5 subjects in each pool. Pooling samples shown by statistical analysis [9] to decrease noise and, thereby, increase the reliability of the determination, has been used in a proteomic analysis of bronchoalveolar lavage proteins [10]. The membrane proteins in control and Alzheimer pooled samples were isolated using three different approaches: (1) membrane preparation in $\mathrm{pH} 7.4$ buffer followed by solubilization with $2 \%$ SDS (Run 1); (2) membrane preparation in $\mathrm{pH}$ 8.0 buffer ( $\mathrm{pH} 8$ minimizes haemoglobin binding to the membrane) followed by solubilization with $2 \%$ SDS (Run 2 ); and (3) membrane preparation in $\mathrm{pH} 7.4$ buffer followed by solubilization with SIGMA Protein Extraction Reagent Type 4 (normally used for 2D electrophoresis, Run 3). Each of these preparations of membrane proteins was resolved through SDS-PAGE. After staining and de-staining of the gels, sample lanes were sliced as shown in Figure 1 (Run 1), and subjected to in-gel trypsin digestion of proteins prior to elution of peptides for analysis by LC-MS-MS. Thus, there were three sets of data obtained from the analysis of proteins prepared by three different approaches (Runs 1-3). By incorporating three different methods of $\mathrm{RBC}$ membrane protein isolation in this study, conclusions from RBC proteome analysis were believed to be independent of the methods used.

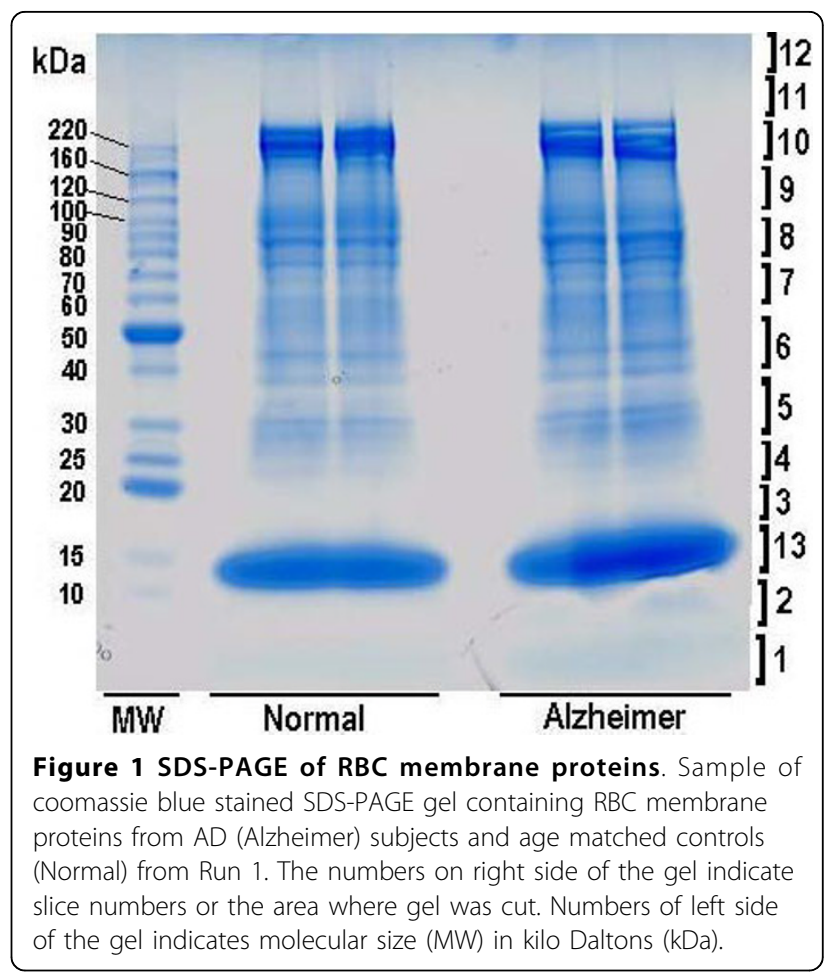

\section{Calculation of Spectral Intensity ratios from LC-MS-MS data}

We detected a total of 785 proteins in normal and AD samples using LC-MS-MS data of three runs and their analysis with Agilent's Spectrum Mill software as described in the methods. The autovalidation feature of this software is unique and has been successfully used by several investigators [11-13]. Some proteins were found to be present in one, two or all three runs of both AD and control samples, while some were found only in AD or control samples. There were also significant differences in the levels of certain proteins for AD and control samples. Several criteria were used to determine which proteins displayed a significant increase or decrease in their level in samples from AD subjects in comparison to samples from normal control subjects. (1) Protein entries with only one peptide match - considered insignificant were removed. This step removed 170 proteins, leaving 615 proteins for further consideration. (2) To make the data more reliable, proteins with a unique score less than 25 were deleted. This step reduced the number of proteins to 548. (3) Proteins detected only in one run - considered insignificant - were eliminated. This step reduced the list of proteins to 224. (4) Among these 224 proteins, three accession numbers had no specific protein name or little available information - and so, were not considered in the present study. (5) Among the rest of the 221 proteins, there were two proteins observed only in AD subjects, while 26 proteins were observed solely in normal 
subjects. The proteins exclusively present or absent in samples from AD subjects represent potential biomarkers. However, the identification of a biomarker would require validation for the protein assignment and a demonstration that the changes were present in a number of individual subjects. Such an analysis was beyond the scope of this study and will be considered in a future publication.

In this study, we focused our attention on the 193 proteins detected in both $\mathrm{AD}$ and control samples. Although, care was taken to minimize contamination of platelets and nucleated cells during RBC isolation, minor contamination may still be possible, which might contribute to these 193 proteins. The mean intensities of these proteins are compared for AD subjects and controls using data from equivalent number of runs from each group (Figure 2 scattered points). The line shown in Figure 2 was generated for equivalent intensities in both groups of subjects. Points to the right of the line indicate proteins with elevated intensities in the AD subjects and points to the left of the line indicate proteins with elevated intensities in normal subjects. Figure 2 indicates that there are a number of proteins with appreciable differences in intensities when both groups are compared. We focused our analysis on those proteins. To evaluate significant changes between AD and normal subjects, the total spectral intensities for each of the 193 proteins were added separately and the ratios of the corresponding total intensities (AD/normal) were calculated. Thus, for a

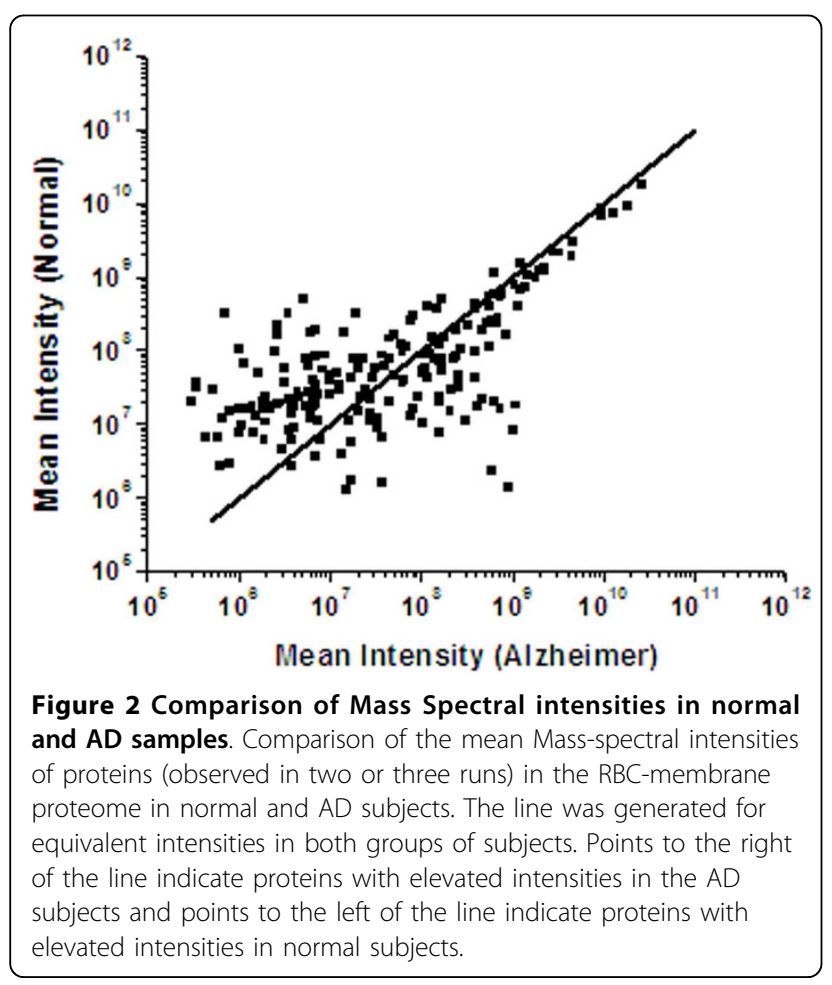

particular protein, a ratio value greater or lesser than 1 would indicate an increase or decrease respectively in its level in the AD subjects. However, to make our data more reliable, we considered a ratio of 1.5 or more (1.5-fold or more increase) for a protein to be significantly increased in AD subjects. Similarly, a ratio of 0.67 or lower (1.5-fold or more decrease) for a protein was considered significant to conclude that the level of that protein decreased in AD subjects. Thus proteins with a ratio of greater than 0.67 and less than 1.5 were eliminated from further consideration.

These above criteria reduced the number of proteins being considered to 160 . These proteins along with the change in their respective level (AD/normal), their IPI accession numbers, and their linked gene names are presented in a separate table as Supplementary material (Additional file 1). Most of the proteins listed in this table have been previously reported to be present in the RBC proteome [7]. Proteins shown in bold were reported to be present in the $\mathrm{RBC}$ membrane proteome by Pasini et. al. [8], and proteins with asterisks have been reported to be present in the whole RBC proteome by Goodman et. al. [7]. To analyze further, we have focused on two groups of proteins, one that is involved with RBC cell morphology and the other, which has been reported by other investigators in AD as well as in animal models of the disease.

\section{Level of Membrane/Cytoskeleton proteins linked to RBC morphology are altered in AD subjects}

There is evidence for the formation of RBCs with altered morphology in AD subjects $[1,14,15]$, which reflect perturbations impairing the required deformability of the RBC. This deformability is accomplished by a cytoskeleton on the cytoplasmic side of the RBC membrane that consists of spectrin tetramers $(2 \alpha$ and $2 \beta$ chains). The cytoskeleton is linked to the membrane by a network of proteins that participate in both horizontal and vertical interactions [16]. The spectrin hetero-dimer is anchored to the plasma membrane via two vertical attachment sites. The first attachment site is assembled by the band 3-ankyrin complex that binds to a site near the carboxyl terminus of $\beta$-spectrin, providing a mechanism, by which the "head" region of the spectrin hetero-dimer binds to the cytoplasmic surface of the plasma membrane [16-18]. This linkage is strengthened by the protein band 4.2 . The second vertical bridge is located at the "tail" region of the spectrin hetero-dimer and is composed of several proteins collectively known as the "junctional complex" $[19,20]$. This region of spectrin is associated with actin protofilaments, which are bound to adducin and tropomyosin and linked to glycophorin $C$ via band 4.1 and dematin (band 4.9). Tropomodulin-1 is a well defined actin-capping protein that 
interacts with tropomyosin at the pointed end of actin filaments [21]. This junctional complex has been shown to play a critical role in the maintenance of erythrocyte elasticity, shape and membrane stability $[16,18,20]$. Changes in the level of one or more of these proteins may contribute to decreased deformability of RBC, leading to the decrease in blood flow through the microcirculation, impaired oxygen delivery and consequently to AD pathology $[1,22]$.

Our proteomic study of the RBC membrane in AD subjects makes it possible to explain these morphology/ shape changes. In Table 1, we have listed the proteins involved in the cytoskeleton network that are altered in AD subjects relative to the normal controls. Our results suggest that the level of band 4.2 protein increased by $70 \%$ in AD subjects. This increase may alter the proper balance between band 4.2 and the link of the membrane to the spectrin head. With respect to the junctional complex involving the spectrin tail, there are significant changes in the level of a number of proteins including tropomodulin, tropomyosin, adducin, glycophorin, dematin, and the F-actin capping protein. In addition, we have also observed changes in the level of ezrin which contains the $\mathrm{N}$-terminal band 4.1 sequence

Table 1 Alteration in the level of RBC membrane/ cytoskeletal proteins related to cell morphology

\begin{tabular}{|c|c|c|}
\hline $\begin{array}{l}\text { Accession } \\
\text { No. }\end{array}$ & $\begin{array}{l}\text { Fold Change } \\
\text { (AD/Normal) }\end{array}$ & Protein Name \\
\hline IPI00028120 & 1.71 & $\begin{array}{l}\text { Erythrocyte membrane protein } \\
\text { band } 4.2\end{array}$ \\
\hline IPI00220741 & 1.83 & Spectrin alpha chain, erythrocyte \\
\hline IPI00216704 & 2.07 & $\begin{array}{l}\text { Splice isoform } 2 \text { of P11277 Spectrin } \\
\text { beta chain, erythrocyte* }\end{array}$ \\
\hline IPI00002375 & 2.88 & Tropomodulin 1 \\
\hline IPI00218319 & 2.15 & $\begin{array}{l}\text { Splice isoform } 2 \text { of P06753 } \\
\text { Tropomyosin alpha } 3 \text { chain } \\
\text { (tropomyosin } 3 \text { isoform 2) }\end{array}$ \\
\hline IPI00220158 & 0.43 & $\begin{array}{l}\text { Splice isoform } 3 \text { of P35611 Alpha } \\
\text { adducin (Erythrocyte adducin } \\
\text { subunit alpha)* }\end{array}$ \\
\hline IPI00026299 & 4.03 & $\begin{array}{l}\text { Splice isoform of P04921 } \\
\text { Glycophorin C }\end{array}$ \\
\hline IPI00216311 & 5.11 & $\begin{array}{l}\text { Villin } 2 \text { (cytovillin 2; Ezrin) (has } \\
\text { high degree of similarity within its } \\
\text { N-terminal domain to the } \\
\text { erythrocyte cytoskeletal protein, } \\
\text { band } 4.1 \text {, Gould et al., EMBO } \\
\text { Journal vol.8 no.13 pp.4133-4142, } \\
\text { 1989)* }\end{array}$ \\
\hline IPI00005969 & 7.84 & $\begin{array}{l}\text { F-actin capping protein alpha-1 } \\
\text { subunit }\end{array}$ \\
\hline IPI00292290 & 0.3 & $\begin{array}{l}\text { Splice isoform Long of Q08495 } \\
\text { Dematin (Erythrocyte membrane } \\
\text { protein band } 4.9)^{*}\end{array}$ \\
\hline
\end{tabular}

N.B. Proteins shown in bold letters have been reported by Pasini et. al. [8] to be present in RBC membrane and those with asterisks have been reported by Goodman et. al. [7] to be present in whole RBC proteome. involved in binding to glycophorin. Interestingly, all of the above stated proteins were implicated in changes in RBC stability. However, the decrease in adducin and dematin is of particular interest because of a study by Chen et. al. [23], in which it has been shown that the reduction in the level of either dematin or $\beta$-adducin exerted modest effects on RBC shape and stability, with a more pronounced effect when both proteins are reduced/eliminated. These changes taken together suggest altered morphology with decreased deformability and stability of the RBCs in AD subjects.

Level of other Membrane/Cytoskeleton proteins linked to Alzheimer's disease are also altered in RBC of AD subjects There is extensive literature describing changes in protein levels associated with AD. Most of these studies are focused on brain tissue in both human and animal models. It is, possible to observe similar changes in RBC membrane if the activation or inhibition of protein synthesis observed in AD brains affect protein synthesis in other tissues including RBCs. Alternatively, the observed changes in $\mathrm{RBC}$ membrane from $\mathrm{AD}$ subjects may reflect proteins that are taken up by RBCs when they come in contact with these tissues [24-26]. For both of these reasons, changes in RBC membrane proteins can be used to monitor changes in AD pathology. Therefore, we searched the literature to find if any of the proteins in our RBC membrane proteome (Additional file 1) have any link to AD. We looked for correlations with the reported change in human AD subjects or in an animal model of AD. Proteins, showing similar changes in both our study as well as in existing AD literature are listed in Table 2.

Adenylyl cyclase-associated protein, a transport/cytoskeleton protein, was found to be 2.2 fold up-regulated in presenilin knockout mice having neurodegeneration [27]. Oxidative stress has been implicated in $\mathrm{AD}$ and has been reported to be elevated in presenilin knockout mice independent of brain $A \beta$ deposition $[28,29]$. Aluminiuminduced oxidative stress in rat brain was shown to increase the level of aminolevulinic acid dehydratase (ALAD) in blood [30]. Hypoxia, known to cause oxidative stress, was elevated in clinical AD [31], causing an increase in stress response proteins such as heat shock 90 kDa protein 1 alpha (HSP90) [32,33]. For HSP90 we confirmed our MS data (Table 2) using western blot analysis of RBC membrane proteins with a monoclonal HSP90 antibody, showing an elevation of HSP90 in four out of five $\mathrm{AD}$ subjects (Figure 3). An increase in the oxidative stress in AD is expected to result in an elevation $[34,35]$ of catalase in AD subjects as we noticed (Table 2). Aquaporin 1 (AQP1) expression in the cerebral cortex was shown to have been increased at early stages of Alzheimer disease [36]. Calgranulin B (S100A9), an inflammation-associated protein was reported to be expressed in 
Table 2 Alteration in the level of RBC membrane/cytoskeletal proteins similar to those alterations in AD or its animal model

\begin{tabular}{lclc}
\hline Accession No. & Fold Change (AD/Normal) & Protein Name & Citations showing Similar fold changes \\
\hline IPI00008274 & 8.13 & Adenylyl cyclase-associated protein & {$[27]$} \\
IPI00010314 & 1.78 & Aminolevulinate, delta-, dehydratase & {$[30]$} \\
IPI00024689 & 2.61 & Aquaporin-CHIP (Aquaporin-1, AQP-1, AQP1) & {$[36]$} \\
IPI00027462 & 3.38 & Calgranulin B (S100A9) & {$[37]$} \\
IPI00233820 & 2.61 & Catalase* & {$[54,55]$} \\
IPI00027438 & 1.89 & Flotillin-1 & {$[38]$} \\
IPI00328602 & 123.42 & heat shock 90 kDa protein 1, alpha & {$[33,56]$} \\
IPI00217966 & 634.23 & L-lactate dehydrogenase A* & {$[39]$} \\
IPI00298860 & 2.88 & Lactotransferrin precursor (Lactoferrin) & {$[40]$} \\
IPI00218342 & 31.93 & [Contains: Lactoferroxin A & {$[41]$} \\
IPI00022434 & 2.08 & Methylenetetrahydrofolate dehydrogenase 1 & {$[43]$} \\
IPI00180818 & 0.18 & (MTHFD1) & {$[44]$} \\
IPI00026119 & 0.19 & Serum albumin precursor & {$[45]$}
\end{tabular}

N.B. Proteins shown in bold letters have been reported by Pasini et. al. [8] to be present in RBC membrane and those with asterisks have been reported by Goodman et. al. [7] to be present in whole RBC proteome.

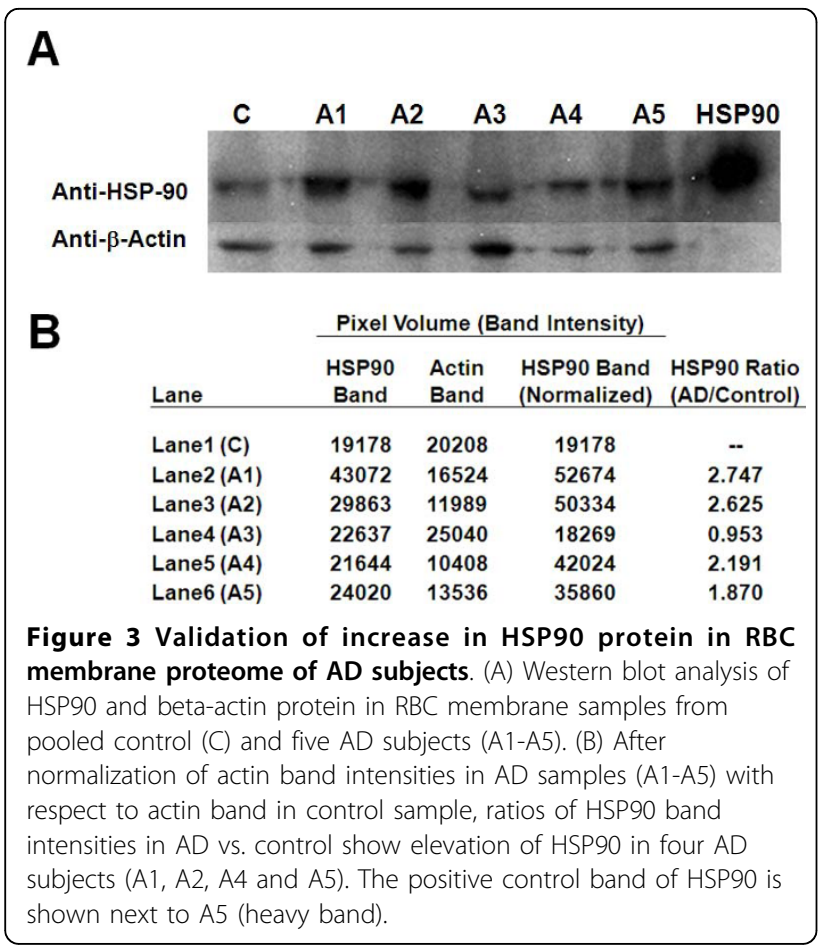

AD but not in normal human brains [37]. According to Girardot et. al. [38], confocal microscopy evidence suggests that flotillin-1 was accumulated most often in tangle-bearing neurons in AD subjects. A report showed a significant increase in specific activity of lactate dehydrogenase A in frontal and temporal cortex of AD brains [39]. Lactotransferrin expression was reported to be upregulated in both neurons and glia in affected AD tissue [40]. It was reported that methylenetetrahydrofolate dehydrogenase 1 (MTHFD1) genotype had a tendency of increased frequency in AD subjects [41]. According to Hye et al. [42], serum albumin precursor was elevated in plasma from $\mathrm{AD}$ subjects and a similar elevation was observed in brain of mouse model AD [43]. In contrast, we have also observed two proteins - aldolase A and Ubiquitin-activating enzyme E1 - whose levels were decreased in $\mathrm{RBC}$ proteome of $\mathrm{AD}$ subjects similar to that reported in $\mathrm{AD}$ hippocampus proteome [44], and AD brain samples respectively [45].

\section{Conclusions}

The present membrane proteomics data suggest two aspects of how changes in the level of proteins in RBC membrane can contribute to our understanding of AD. (1) The shape/morphology changes observed earlier in the $\mathrm{RBC}$ of AD subjects are most likely attributed primarily to the changes in the level of a series of membrane/cytoskeleton proteins that are involved in regulating the shape, stability and elasticity of the RBC membrane. In turn, these changes can alter RBC deformability and impair oxygen transport in $\mathrm{AD}$ subjects. (2) The changes in the level of a second series of proteins in our RBC membrane proteome reflect similar changes reported earlier by other investigators in $\mathrm{AD}$ subjects or animal models of $\mathrm{AD}$. For some of these proteins, such as HSP90 and L-lactate dehydrogenase $\mathrm{A}$, the changes are very dramatic and may be useful for AD diagnosis. We validated the increase of HSP90 in the RBC membrane proteome from AD subjects by using western blot analysis (Figure 3A \&3B). Thus, this study provides a potential link between the RBC membrane proteome changes in AD subjects and AD pathology. The potential significance of this study is indicated by 
the fact that we have been able to detect differences even with subjects in the early stage of AD with only very mild dementia.

\section{Methods \\ Sample Collection}

This investigation of RBC membrane proteome changes in AD subjects was a pilot study of 10 subjects (5 AD subjects and 5 controls) as part of a National Institute on Aging (NIA) approved study "Immune and Other BioMarkers of Alzheimer's Disease" (NIA protocol \# 2005095), which was included in the Wake Forest University School of Medicine Ginkgo Evaluation of Memory Study [46] (GEMS), as reported earlier [1]. Briefly, each AD case was identified based on their scores on a preliminary battery of 3 tests (3MSE, Modified Mini-Mental State Examination (scale 1 to 100) [47], CDR, Clinical Dementia Rating [48] and ADAS, Alzheimer's Disease Assessment Scale [49]) followed by a full neuropsychological battery (NPB), a standardized examination by a neurologist and a brain magnetic resonance imaging (MRI) scan. All these data were then used by a panel with expertise in dementia diagnosis to confirm dementia incidence and classify according to dementia subtype. This procedure made it possible to diagnose subjects in the early stage of AD. Thus, all AD subjects were at an early stage of AD with very mild dementia (a CDR of 0.5 and 3MSE score as low as 70). Control cases were matched for age and cardiovascular disease history with 3MSE score of 90 or above. None of the subjects reported any incidence of disease that required hospitalization including cardiovascular disease such as angina, Congestive heart failure (CHF), stroke/Transient ischemic attack (TIA) or Peripheral vascular disease (PVD) during 6 months prior to sample collection. Characteristics of all participants in our RBC proteome study as regards their age, gender, medications used are listed in Table 3.

Blood samples from five AD subjects and five agematched controls were collected in heparinised (green cap) tubes at Roena Kulynych Center, Wake Forest University School of Medicine (Winston-Salem, North Carolina). Blood was centrifuged at low speed $(\sim 1125 \times \mathrm{g})$ to remove plasma. The pelleted cells were washed three times (each time a portion of top layer of $\mathrm{RBC}$ removed to minimize contamination of nucleated cells) with phosphate buffered saline (PBS) containing $100 \mu \mathrm{M}$ disodium EDTA. Washed red blood cells (pellets) were shipped frozen on dry ice to our NIA laboratory at Baltimore for further processing. Samples upon receipt were stored at $-150^{\circ} \mathrm{C}$.

\section{Isolation of membrane proteins}

Membrane proteins were isolated from $\mathrm{RBC}$ pellets shipped overnight in dry ice and stored frozen at $-150^{\circ} \mathrm{C}$. Frozen $\mathrm{RBC}$ pellets were thawed in the presence of $1 \mathrm{mM}$
Table 3 Personal and medication data of AD (A1-A5) and control (C1-C5) subjects used in this study

\begin{tabular}{cccc}
\hline Subject & Gender & Age & Medications taken \\
\hline A1 & Female & 81 & ESTRGN \\
\hline A2 & Female & 84 & ACED, NTCA, THRY, HTNMED \\
\hline A3 & Male & 89 & ASA \\
\hline A4 & Male & 99 & ADPI, ASA, HCTZ \\
\hline A5 & Male & 85 & ALZH \\
\hline C1 & Female & 83 & ASA, BETA, LOOP, DIUR, HTNMED \\
\hline C2 & Female & 91 & ASA, COX2, THRY \\
\hline C3 & Male & 87 & ASA, DLTIR, NSAID, CCBIR, CCB, HTNMED \\
\hline C4 & Male & 87 & HCTZ, PPI, DIUR, HTNMED \\
\hline C5 & Male & 85 & None \\
\hline
\end{tabular}

N.B. Medication abbreviations are ACED (Ace inhibitors with diuretics), ADPI (Inhibitors of ADP-induced platelet aggregation), ALZH (Acetylcholine esterase inhibitors for AD), ASA (Aspirin), BETA (Beta-blockers without diuretics), CCB (Any Calcium-channel blocker = CCIR OR CCBSR OR CCBT), CCBIR (Immediaterelease CCBS = NIFIR OR DIHIR OR VERIR OR DLTIR), CCBT (T-type Calciumchannel blocker), COX2 (COX-2 inhibitors (NSAID Agents); separate from NSAID variable), DIHIR (Immediate-release Dihydropyridines other than Nifedipine), DIUR (Any diuretic), DLTIR (Immediate-release Diltiazem), ESTRGN (Estrogens, excluding vaginal creams), HCTZ (Thiazide diuretics without Ksparing agents), HTNMED (Any anti-hypertensive medication), LOOP (Loop diuretics), NIFIR (Immediate-release Nifedipine), NSAID (Non-steroidal antiinflammatory agents, excluding Aspirin), NTCA (Non-tricyclic antidepressants other than MAO Inhibitors), PPI (Proton pump inhibitors), THRY (Thyroid agents), VERIR (Immediate-release Verapamil),

(final conc.) phenyl methyl sulfonyl fluoride (PMSF) a serine protease inhibitor by adding a stock solution of 100 mM PMSF in ethanol to the cell pellet. PMSF is well documented as an irreversible serine protease inhibitor in the $\mathrm{pH}$ range of 4 to $8.5[50,51]$ and has been used in proteomic studies [52]. After thawing, $100 \mu$ laliquots of the cell pellet from each of the 5 control samples and from each of the five Alzheimer's samples were pooled separately resulting in a final volume of $500 \mu$ for each category. In order to take into account potential variability in membrane protein solubilization, three different conditions (Runs 1-3) were used to prepare membranes and solubilize them. Cells in the pool of RBC pellets were lysed by diluting them by the addition of $9 \mathrm{ml}$ of $10 \mathrm{mM}$ Phosphate buffer, $\mathrm{pH} 7.4$ (Runs 1 and 3) or $9 \mathrm{ml}$ of $5 \mathrm{mM}$ Phosphate buffer, $\mathrm{pH} 8.0$ (condition used to prepare white ghosts [6] (Run 2)). In each buffer, inhibition of proteolysis was also maintained by the addition of PMSF ( $1 \mathrm{mM}$ final conc.). Hemolysates were centrifuged either at $\sim 39,000 \times$ g (Runs 1 and 3) or at $\sim 9000 \times \mathrm{g}$ [6] (Run 2) for $30 \mathrm{~min}$. Membrane pellets were resuspended in $10 \mathrm{mM}$ Phosphate buffer, pH 7.4 (Runs 1 and 3) or $5 \mathrm{mM}$ Phosphate buffer, $\mathrm{pH} 8.0$ (Run 2) and washed by centrifuging at $\sim 39,000 \times \mathrm{g}$ (Runs 1 and 3) or at $\sim 20,000 \times \mathrm{g}$ [6] (Run 2) until the supernatant was clear. Membrane pellets were solubilized by vortexing with $500 \mu \mathrm{l}$ of either of $10 \mathrm{mM}$ Tris. $\mathrm{HCl}, \mathrm{pH}$ 7.4 containing 2\% SDS (Runs 1 and 2) or SIGMA Protein Extraction Reagent Type 4(Run 3) containing urea, 
thiourea, Tris, and detergent $\mathrm{C} 7 \mathrm{BzO}$. Insoluble debris was removed by spinning at $\sim 39,000 \times \mathrm{g}$ (Runs 1 and 3 ) or at $\sim 14,000 \times \mathrm{g}$ [6] (Run 2) for $30 \mathrm{~min}$. Protein assay in the clear supernatants from runs 1 and 2 were performed using BCA reagent from Pierce, while protein assay in the clear supernatant from run 3 was performed using BIORAD Bradford reagent, since urea and thiourea interfered with the BCA assay.

\section{SDS-PAGE Analysis}

Samples with $\sim 50 \mu \mathrm{g}$ (Runs 1 and 2, two lanes each) or $100 \mu \mathrm{g}$ (Run 3, one lane each) per lane of RBC membrane proteins from control and Alzheimer's subjects were subjected to SDS-Polyacrylamide gel electrophoresis (SDS-PAGE) under reducing conditions on commercial small gradient (NOVEX, 4-20\%) gels (Runs 1 and 2) or on regular size gradient gel (Jules Inc., 4-20\%) (Run 3). Following electrophoresis, gels were stained with coomassie blue. Then each gel was carefully laid on a glass plate and horizontal slices were cut with new razor blades for each sample. Each slice was cut into $\sim 1$ $\mathrm{mm}$ cubes and the pieces were transferred to the corresponding labelled-microfuge tube.

\section{Tryptic digestion}

Gel pieces were destained with $25 \%$ acetonitrile in $25 \mathrm{mM}$ ammonium bicarbonate (three times), and were dehydrated with $400 \mu \mathrm{l}$ of $100 \%$ acetonitrile followed by vacuum drying. Proteins in the gel pieces were then subjected to reductive alkylation by adding $10 \mathrm{mM}$ DTT in $5 \mathrm{mM}$ ammonium bicarbonate, incubating the tubes at $55^{\circ} \mathrm{C}$ for $45 \mathrm{~min}$, subsequently aspirating the liquid, and incubating the gel pieces with $150 \mu \mathrm{l}$ of $55 \mathrm{mM}$ iodoacetamide in the same buffer in the dark. Residual DTT and iodoacetamide were washed off the gel pieces with $5 \mathrm{mM}$ ammonium bicarbonate (four times) and dehydrated for $10 \mathrm{~min}$ by the addition of $400 \mu \mathrm{l}$ of $100 \%$ acetonitrile. Proteins in gel pieces were then digested overnight with Trypsin Gold, (Mass Spectrometry Grade) from Promega (trypsin: protein was about $1: 20$ ) at $37^{\circ} \mathrm{C}$ to obtain the corresponding peptides. The peptides were then eluted from gel pieces with $50 \%$ Acetonitrile, $45 \%$ HPLC grade water, and $0.5 \%$ formic acid (two times) and once with $100 \%$ acetonitrile. The eluted fractions were pooled, dried in a SpeedVac (Savant ThermoFisher), and dissolved in $10 \mu \mathrm{l}$ of sample buffer (5\% acetonitrile, $0.1 \%$ formic acid, 97.9\% HPLC grade water).

\section{LC-MS-MS}

Samples $(10 \mu \mathrm{l})$ were injected by an auto-injector (CTCAutosampler, CTC Analytics) with a flow rate of $500 \mathrm{nl} / \mathrm{min}$ into a LTQ linear ion trap mass spectrometer (ThermoElectron) for LC-MS-MS analysis as described by
Johanssen et. al. [53]. During LC, a linear gradient from 95\% mobile phase A (2\% acetonitrile, $0.1 \%$ formic acid, $97.9 \%$ HPLC grade water) to $90 \%$ mobile phase B (2\% HPLC grade water, $0.1 \%$ formic acid, $97.9 \%$ acetonitrile) was used for $110 \mathrm{~min}$ followed by $95 \%$ mobile phase A for $10 \mathrm{~min}$. The peptides were detected in positive ion mode in the mass spectrometer using a data-dependent method in which the seven most abundant ions detected in an initial survey scan were selected for MS-MS analysis. Each scan cycle consisted of one full scan mass spectrum ( $\mathrm{m} / \mathrm{z}$ 400-1800) collected in profile mode followed by six MS-MS events in centroid mode.

\section{Peptide Database Search}

Raw MS-MS data were analyzed by Spectrum Mill proteomics software (Rev A03.02.060, Agilent Technologies, Santa Clara, CA) after extracting them under default conditions. The extracted files were searched against the human non-redundant International Protein Index (IPI) human sequence database http://www.ebi.ac.uk using trypsin as the protease allowing for a maximum of three missed cleavages, including fixed modification of carbamidomethylation and variable modifications of oxidized methionine and $\mathrm{N}$-terminal glutamine conversion to pyroglutamic acid in the search. Only proteins with at least two validated peptides and a total score 25 or more were considered valid for reporting. To compare identified proteins between $\mathrm{AD}$ and normal groups, the number of spectra and the summed ion intensity of peptides for each protein (total ion intensity) were used as indicators of protein amounts. Because these were semi quantitative metrics, we added total intensities for each protein in all three runs for $\mathrm{AD}$ and normal subjects separately - then divided them to calculate ratio $\mathrm{AD} /$ normal determining if the protein level was elevated (greater than or equal to 1.5) or reduced (less than or equal to 0.67 ) in $\mathrm{AD}$ subjects. Cellular locations of the proteins were determined by using ProteinCenter program version 2.01 (PROXEON, Denmark).

\section{Western blot analysis}

Western blot analysis of HSP90 along with cell standard beta-actin protein was performed on $\mathrm{RBC}$ membrane proteins isolated from pooled samples of control subjects and individual samples of five AD subjects prepared as described above. Proteins (50 $\mu \mathrm{g}$ per lane) were separated by SDS-PAGE on NOVEX 4-12\% Tris-glycine gels, blotted to PVDF membranes, and probed for HSP90 and beta-actin by using a mouse monoclonal anti-HSP90 (BD Biosciences) and a rabbit polyclonal anti-actin (Santa Cruz Biotechnology) antibody (both at 1:1000 dilution) and WesternBreeze Chemiluminescent Kits (anti-mouse and anti-rabbit) from Invitrogen 
respectively. Band intensities of HSP-90 and actin bands in the western blot were quantitated upon scanning the blot and measuring the band pixel volume by ImageQuant TL software (GE Healthcare).

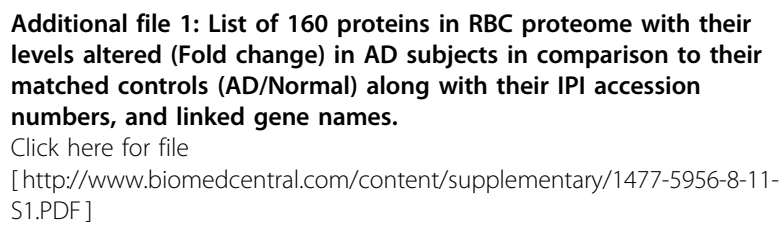

\section{Acknowledgements}

This research was supported entirely by the Intramural Research Program of $\mathrm{NIA}, \mathrm{NIH}$ although blood samples were obtained from Wake Forest

University. We are thankful to Agilent Technologies for their help in analysis of RBC membrane proteome MS-MS data by SpectrumMill software. There is no potential conflict with any institutions where work was done. This is to state that all financial and material support for this research has been born by the above mentioned two institutions, and there are no potential conflicts. We are also thankful to Dr. Michel Bernier of NIA for providing us a sample of cell extract expressing high level of HSP-90 for our positive control, anti-HSP90 and anti-actin antibodies for western blot analysis as a gift.

\section{Author details}

${ }^{1}$ National Institute on Aging, Baltimore, MD, USA. ${ }^{2}$ Wake Forest University, Winston-Salem, NC, USA. ${ }^{3}$ National Institute on Aging, Bethesda, MD, USA.

\section{Authors' contributions}

JGM conceived the idea of proteomics study, prepared RBC membrane protein samples, did SDS-PAGE, performed major portion of the sample analysis and drafted the manuscript. HDS performed the gel slicing, in-situ trypsin digestion, LC/MS of peptides and helped in the analysis of the proteomics data. JDW provided the Alzheimer and control blood samples and was involved in setting up the study to compare Alzheimer and control blood samples. LJL participated in the plans to compare Alzheimer and control blood samples. SS oversaw the proteomic analysis of the samples. JMR conceived the study and participated in its design. All authors read and approved the final manuscript.

\section{Competing interests}

The authors declare that they have no competing interests.

Received: 29 September 2009 Accepted: 3 March 2010

Published: 3 March 2010

\section{References}

1. Mohanty JG, Eckley DM, Williamson JD, Launer LJ, Rifkind JM: Do red blood cell-beta-amyloid interactions alter oxygen delivery in Alzheimer's disease? Adv Exp Med Biol 2008, 614:29-35.

2. Ravi LB, Poosala S, Ahn D, Chrest FJ, Spangler EL, Jayakumar R, et al: Red cell interactions with amyloid-beta(1-40) fibrils in a murine model. Neurobiol Dis 2005, 19:28-37.

3. Ravi LB, Mohanty JG, Chrest FJ, Jayakumar R, Nagababu E, Usatyuk PV, et al: Influence of beta-amyloid fibrils on the interactions between red blood cells and endothelial cells. Neurol Res 2004, 26:579-585.

4. Goodman SR, Krebs KE, Whitfield CF, Riederer BM, Zagon IS: Spectrin and related molecules. CRC Crit Rev Biochem 1988, 23:171-234.

5. Steck TL: The organization of proteins in the human red blood cell membrane. A review. J Cell Biol 1974, 62:1-19.

6. Low TY, Seow TK, Chung MC: Separation of human erythrocyte membrane associated proteins with one-dimensional and twodimensional gel electrophoresis followed by identification with matrixassisted laser desorption/ionization-time of flight mass spectrometry. Proteomics 2002, 2:1229-1239.
7. Goodman SR, Kurdia A, Ammann L, Kakhniashvili D, Daescu O: The human red blood cell proteome and interactome. Exp Biol Med (Maywood) 2007, 232:1391-1408

8. Pasini EM, Kirkegaard M, Mortensen P, Lutz HU, Thomas AW, Mann M: In-depth analysis of the membrane and cytosolic proteome of red blood cells. Blood 2006, 108:791-801.

9. Kendziorski CM, Zhang $Y$, Lan $H$, Attie AD: The efficiency of pooling mRNA in microarray experiments. Biostatistics 2003, 4:465-477.

10. Plymoth A, Yang Z, Lofdahl CG, Ekberg-Jansson A, Dahlback M, Fehniger TE, et al: Rapid proteome analysis of bronchoalveolar lavage samples of lifelong smokers and never-smokers by micro-scale liquid chromatography and mass spectrometry. Clin Chem 2006, 52:671-679.

11. Fandino AS, Rais I, Vollmer M, Elgass H, Schagger H, Karas M: LCnanospray-MS/MS analysis of hydrophobic proteins from membrane protein complexes isolated by blue-native electrophoresis. J Mass Spectrom 2005, 40:1223-1231.

12. Horth P, Miller CA, Preckel T, Wenz C: Efficient fractionation and improved protein identification by peptide OFFGEL electrophoresis. Mol Cell Proteomics 2006, 5:1968-1974.

13. Stevens AL, Wishnok JS, Chai DH, Grodzinsky AJ, Tannenbaum SR: A sodium dodecyl sulfate-polyacrylamide gel electrophoresis-liquid chromatography tandem mass spectrometry analysis of bovine cartilage tissue response to mechanical compression injury and the inflammatory cytokines tumor necrosis factor alpha and interleukin-1beta. Arthritis Rheum 2008, 58:489-500.

14. Goodall HB, Reid AH, Findlay DJ, Hind C, Kay J, Coghill G: Irregular distortion of the erythrocytes (acanthocytes, spur cells) in senile dementia. Dis Markers 1994, 12:23-41.

15. Chang CY, Liang HJ, Chow SY, Chen SM, Liu DZ: Hemorheological mechanisms in Alzheimer's disease. Microcirculation 2007, 14:627-634

16. LUX SE, Palek J: Principles and Practice of Hematology. BLOOD Philadelphia: J. B. LippincottHandin RI, Lux SE, Stossel TP 1995, 1701-1718.

17. Luna EJ, Hitt AL: Cytoskeleton-plasma membrane interactions. Science 1992, 258:955-964.

18. Chasis JA, Mohandas N: Red blood cell glycophorins. Blood 1992, 80:1869-1879.

19. Bennett $V$ : The spectrin-actin junction of erythrocyte membrane skeletons. Biochim Biophys Acta 1989, 988:107-121.

20. Gilligan DM, Bennett $\mathrm{V}$ : The junctional complex of the membrane skeleton. Semin Hematol 1993, 30:74-83.

21. Fowler VM: Tropomodulin: a cytoskeletal protein that binds to the end of erythrocyte tropomyosin and inhibits tropomyosin binding to actin. J Cell Biol 1990, 111:471-481.

22. Sun X, He G, Qing H, Zhou W, Dobie F, Cai F, et al: Hypoxia facilitates Alzheimer's disease pathogenesis by up-regulating BACE1 gene expression. Proc Natl Acad Sci USA 2006, 103:18727-18732.

23. Chen H, Khan AA, Liu F, Gilligan DM, Peters LL, Messick J, et al: Combined deletion of mouse dematin-headpiece and beta-adducin exerts a novel effect on the spectrin-actin junctions leading to erythrocyte fragility and hemolytic anemia. J Biol Chem 2007, 282:4124-4135

24. Nayak CD, Nayak DM, Raja A, Rao A: Erythrocyte indicators of oxidative changes in patients with graded traumatic head injury. Neurol India 2008 56:31-35.

25. Parmahamsa M, Reddy KR, Varadacharyulu N: Changes in composition and properties of erythrocyte membrane in chronic alcoholics. Alcohol Alcohol 2004, 39:110-112.

26. Campbell BC, Meredith PA, Moore MR, Goldberg A: Erythrocyte deltaaminolaevulinic acid dehydratase activity and changes in deltaaminolaevulinic acid concentration in various forms of anaemia. $\mathrm{Br} J$ Haematol 1978, 40:397-400

27. Beglopoulos V, Sun X, Saura CA, Lemere CA, Kim RD, Shen J: Reduced beta-amyloid production and increased inflammatory responses in presenilin conditional knock-out mice. J Biol Chem 2004, 279:46907-46914.

28. Zhu M, Gu F, Shi J, Hu J, Hu Y, Zhao Z: Increased oxidative stress and astrogliosis responses in conditional double-knockout mice of Alzheimer-like presenilin-1 and presenilin-2. Free Radic Biol Med 2008.

29. Gu F, Zhu M, Shi J, Hu Y, Zhao Z: Enhanced oxidative stress is an early event during development of Alzheimer-like pathologies in presenilin conditional knock-out mice. Neurosci Lett 2008, 440:44-48.

30. Flora SJ, Mehta A, Satsangi K, Kannan GM, Gupta M: Aluminum-induced oxidative stress in rat brain: response to combined administration of 
citric acid and HEDTA. Comp Biochem Physiol C Toxicol Pharmacol 2003, 134:319-328.

31. Summers WK: Alzheimer's disease, oxidative injury, and cytokines. J Alzheimers Dis 2004, 6:651-657.

32. Anthony SG, Schipper HM, Tavares R, Hovanesian V, Cortez SC, Stopa EG, et al: Stress protein expression in the Alzheimer-diseased choroid plexus. J Alzheimers Dis 2003, 5:171-177.

33. Ning W, Chu TJ, Li CJ, Choi AM, Peters DG: Genome-wide analysis of the endothelial transcriptome under short-term chronic hypoxia. Physiol Genomics 2004, 18:70-78

34. Rohrdanz E, Schmuck G, Ohler S, Kahl R: The influence of oxidative stress on catalase and MnSOD gene transcription in astrocytes. Brain Res 2001, 900:128-136.

35. Rohrdanz E, Schmuck G, Ohler S, Tran-Thi QH, Kahl R: Changes in antioxidant enzyme expression in response to hydrogen peroxide in rat astroglial cells. Arch Toxicol 2001, 75:150-158.

36. Perez E, Barrachina M, Rodriguez A, Torrejon-Escribano B, Boada M, Hernandez I, et al: Aquaporin expression in the cerebral cortex is increased at early stages of Alzheimer disease. Brain Res 2007, 1128:164-174.

37. Shepherd CE, Goyette J, Utter V, Rahimi F, Yang Z, Geczy CL, et al: Inflammatory S100A9 and S100A12 proteins in Alzheimer's disease. Neurobiol Aging 2006, 27:1554-1563.

38. Girardot N, Allinquant B, Langui D, Laquerriere A, Dubois B, Hauw JJ, et al: Accumulation of flotillin-1 in tangle-bearing neurones of Alzheimer's disease. Neuropathol Appl Neurobiol 2003, 29:451-461.

39. Bigl M, Bruckner MK, Arendt T, Bigl V, Eschrich K: Activities of key glycolytic enzymes in the brains of patients with Alzheimer's disease. J Neural Transm 1999, 106:499-511.

40. Kawamata T, Tooyama I, Yamada T, Walker DG, McGeer PL: Lactotransferrin immunocytochemistry in Alzheimer and normal human brain. Am J Pathol 1993, 142:1574-1585.

41. Dorszewska J, Florczak J, Rozycka A, Kempisty B, Jaroszewska-Kolecka J, Chojnacka K, et al: Oxidative DNA damage and level of thiols as related to polymorphisms of MTHFR, MTR, MTHFD1 in Alzheimer's and Parkinson's diseases. Acta Neurobiol Exp (Wars) 2007, 67:113-129.

42. Hye A, Lynham S, Thambisetty M, Causevic M, Campbell J, Byers HL, et al: Proteome-based plasma biomarkers for Alzheimer's disease. Brain 2006, 129:3042-3050

43. Sizova D, Charbaut E, Delalande F, Poirier F, High AA, Parker F, et al: Proteomic analysis of brain tissue from an Alzheimer's disease mouse model by two-dimensional difference gel electrophoresis. Neurobiol Aging 2007, 28:357-370.

44. Sultana R, Boyd-Kimball D, Cai J, Pierce WM, Klein JB, Merchant M, et al: Proteomics analysis of the Alzheimer's disease hippocampal proteome. J Alzheimers Dis 2007, 11:153-164.

45. Lopez SM, Morelli L, Castano EM, Soto EF, Pasquini JM: Defective ubiquitination of cerebral proteins in Alzheimer's disease. J Neurosci Res 2000, 62:302-310.

46. DeKosky ST, Fitzpatrick A, Ives DG, Saxton J, Williamson J, Lopez OL, et al: The Ginkgo Evaluation of Memory (GEM) study: design and baseline data of a randomized trial of Ginkgo biloba extract in prevention of dementia. Contemp Clin Trials 2006, 27:238-253.

47. Teng EL, Chui HC: The Modified Mini-Mental State (3MS) examination. J Clin Psychiatry 1987, 48:314-318.

48. Morris JC: Clinical dementia rating: a reliable and valid diagnostic and staging measure for dementia of the Alzheimer type. Int Psychogeriatr 1997, 9(Suppl 1):173-176.

49. Rosen WG, Mohs RC, Davis KL: A new rating scale for Alzheimer's disease. Am J Psychiatry 1984, 141:1356-1364.

50. Gold AM, Fahrney DE: The mechanism of reactivation of phenylmethanesulfonyl alpha-chymotrypsin. Biochem Biophys Res Commun 1963, 10:55-59.

51. Fahrney DE, Gold AM: Sulfonyl Fluorides as Inhibitors of Esterases. I. Rates of Reaction with Acetylcholinesterase, a-Chymotrypsin, and Trypsin. J Amer Chem Soc 1963, 85:997-1000.

52. Karsan A, Pollet I, Yu LR, Chan KC, Conrads TP, Lucas DA, et al: Quantitative proteomic analysis of sokotrasterol sulfate-stimulated primary human endothelial cells. Mol Cell Proteomics 2005, 4:191-204.

53. Johansson C, Samskog J, Sundstrom L, Wadensten H, Bjorkesten L, Flensburg J: Differential expression analysis of Escherichia coli proteins using a novel software for relative quantitation of LC-MS/MS data. Proteomics 2006, 6:4475-4485.

54. Rohrdanz E, Schmuck G, Ohler S, Kahl R: The influence of oxidative stress on catalase and MnSOD gene transcription in astrocytes. Brain Res 2001, 900:128-136.

55. Rohrdanz E, Schmuck G, Ohler S, Tran-Thi QH, Kahl R: Changes in antioxidant enzyme expression in response to hydrogen peroxide in rat astroglial cells. Arch Toxicol 2001, 75:150-158.

56. Anthony SG, Schipper HM, Tavares R, Hovanesian V, Cortez SC, Stopa EG, et al: Stress protein expression in the Alzheimer-diseased choroid plexus. J Alzheimers Dis 2003, 5:171-177.

doi:10.1186/1477-5956-8-11

Cite this article as: Mohanty et al:: Alterations in the red blood cell membrane proteome in alzheimer's subjects reflect disease-related changes and provide insight into altered cell morphology. Proteome Science 2010 8:11.

\section{Submit your next manuscript to BioMed Central and take full advantage of:}

- Convenient online submission

- Thorough peer review

- No space constraints or color figure charges

- Immediate publication on acceptance

- Inclusion in PubMed, CAS, Scopus and Google Scholar

- Research which is freely available for redistribution 